
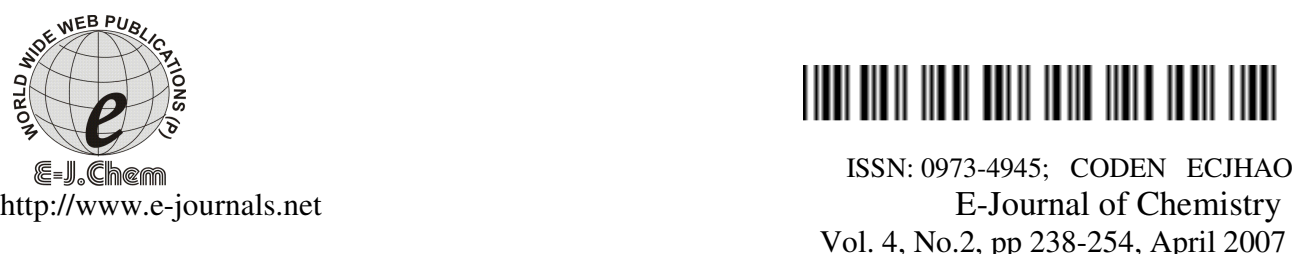

Vol. 4, No.2, pp 238-254, April 2007

\title{
Comparative Study on the Adsorption Kinetics and Thermodynamics of Metal Ions onto Acid Activated Low Cost Pandanus Carbon
}

\author{
R. SUDHA, K. KALPANA, T. RAJACHANDRASEKAR and S. ARIVOLI* \\ P. G. Department of Chemistry, \\ M. R. Government Arts College, \\ Mannargudi 614 001, Tamilnadu, India. \\ E-mail:arivu3636@yahoo.com
}

Received 4 January 2007; Revised 13 February 2007; Accepted 22 February 2007

\begin{abstract}
Batch experiments were carried out for the sorption of Copper and Ferrous ions onto acid activated carbon prepared. The operating variables studied were initial metal ion concentration, $\mathrm{pH}$, and temperature and contact time. The equilibrium data were fitted to the Langmuir and Freundlich isotherm equations. From this adsorption efficiency, adsorption energy, adsorption capacity, intensity of adsorption and dimensionless separation factor were calculated. From the kinetic studies the rate constant values for the adsorption process was calculated. From the effect of temperature thermodynamic parameters like $\Delta \mathrm{G}^{\circ}, \Delta \mathrm{H}^{\circ}$, and $\Delta \mathrm{S}^{\circ}$ were calculated. The mechanism of adsorption for metal ions onto carbon was investigated by using the experimental results and confirmed by FT- IR, XRD and SEM images.
\end{abstract}

Keywords: Adsorption Kinetics, Pandanus Carbon, Langmuir and Freundlich isotherm equations.

\section{Introduction}

The presence of heavy metals in the environment is one of the major concerns because of their toxicity and threat to human life and the environment. Wastewater from industries released into nearby land or rivers without any treatment because the conventional treatment methods are not cost effective in the Indian context ${ }^{1}$. On the other hand, low cost technologies never allow a wishful metal ion removal and it has certain disadvantages. Adsorption is one of the most effective methods and activated carbon is the preferred adsorbent widely employed to treat wastewater containing different metal ions, recognizing the economic drawback of commercial activated carbon. Many investigators have studied 
the feasibility of using inexpensive alternative materials like pearl millet husk, date pits, saw dust buffing dust of leather industry, coir pith, crude oil residue tropical grass, olive stone and almond shells, pine bark, wool waste, coconut shell etc., as carbonaceous precursors for the removal of metals from water and wastewater ${ }^{2,3}$. The present study undertaken to evaluate the efficiency of a carbon adsorbent prepared from acid activated Pandanus carbon for removal of metal ions in aqueous solution. In order to design adsorption treatment systems, knowledge of kinetic and mass transfer processes is essential. In this paper, we report the applicability of kinetic and masstransfer models for the adsorption of Copper and Ferrous ion onto activated carbon.

\section{Experimental}

Dried stem of Pandanus plant were carbonized with concentrated sulphuric acid in the weight ratio of $1: 1(\mathrm{~W} / \mathrm{V})$. The carbonization and activation was completed by heating for twelve hours in a furnace at $400{ }^{\circ} \mathrm{C}$. The resulting carbon washed with distilled water until a constant $\mathrm{pH}$ of the slurry reached. Then the carbon has dried for four hours at $100{ }^{\circ} \mathrm{C}$ in a hot air oven. The dried material was ground well to a fine powder and sieved

All Chemicals used were of high purity, commercially available AnalaR grade. Stock solutions of $1000 \mathrm{mg} / \mathrm{L}$ of metal ions were prepared using doubly distilled water.

Metal ions were made to a known concentration. From that, $50 \mathrm{ml}$ of 5,10,15,20,25 and $30 \mathrm{mg} / \mathrm{L}$ metal ion solutions have taken and added with the $100 \mathrm{mg}$ of activated carbon adsorbent. Then these were agitated at $30,40,50$, and $60{ }^{\circ} \mathrm{C}$ in a defined time intervals. After that the samples were withdrawn from the shaker and filtered. Then they were analyzed in UV-Visible spectrophotometer.

Desorption studies were carried out using the spent carbon. The carbon loaded with metal ion separated and gently washed with distilled water to remove any unasdsorbed metal ions. The metal ions-laden carbons were agitated with $50 \mathrm{~mL}$ each of water, $0.2 \mathrm{M}$ sulphuric acid, hydrochloric acid, and nitric acid and sodium chloride solutions separately for 30 minutes and analyzed. The XRD patterns of the adsorbents before and after adsorption were recorded at the Regional Research Laboratory, Thiruvananthapuram, S.India. The SEM images were taken for the adsorbent at Madurai Kamaraj University, Madurai, S.India.

\section{Results and Discussions}

\section{Effect of contact time and initial metal ion concentration}

The experimental results of adsorptions of Copper ion on the activated carbon at various concentrations $(5,10,15,20,25$ and $30 \mathrm{mg} / \mathrm{L})$ with contact time are shown in Figure 1 . The equilibrium data are given in Table 1. It reveals that, percent adsorption decreased with increase in initial metal ion concentration, but the actual amount of metal ions adsorbed per unit mass of carbon increased with increase in metal ions concentration. It means that the adsorption is highly dependent on initial concentration of metal ions. It is because of at lower concentration, the ratio of the initial number of metal ions to the available surface area is low subsequently the fractional adsorption becomes independent of initial concentration. However, at high concentration the available sites of adsorption becomes fewer and hence the percentage removal of metal ion is dependent upon initial concentration. Equilibrium have established at 40 minutes for all concentrations. Figure 1 reveals that the curves are single, smooth, and continuous, leading to saturation, suggesting the possible monolayer coverage of the metal ions on the carbon surface ${ }^{4,5}$. 
Table 1 Equilibrium parameters for the adsorption of Metal ions onto PD activated Carbon

\begin{tabular}{|c|c|c|c|c|c|c|c|c|c|c|c|c|c|}
\hline \multirow[t]{2}{*}[\mathrm{M}]{$_{0}$} & & \multicolumn{3}{|c|}{$\mathrm{C}_{\mathrm{e}}(\mathrm{mg} / \mathrm{L})$} & \multicolumn{3}{|c|}{$\mathrm{Q}_{\mathrm{e}}(\mathrm{mg} / \mathrm{g})$} & \multirow[b]{2}{*}{$50^{\circ} \mathrm{C}$} & \multirow[b]{2}{*}{$60^{\circ} \mathrm{C}$} & \multicolumn{4}{|c|}{ Metal ion removed (\%) } \\
\hline & & $30^{\circ} \mathrm{C}$ & $40^{\circ} \mathrm{C}$ & $50^{\circ} \mathrm{C}$ & $60^{\circ} \mathrm{C}$ & $30^{\circ} \mathrm{C}$ & $40^{\circ} \mathrm{C}$ & & & $30^{\circ} \mathrm{C}$ & $40^{\circ} \mathrm{C}$ & $50^{\circ} \mathrm{C}$ & $60^{\circ} \mathrm{C}$ \\
\hline 5 & $\approx$ & 1.2520 & 1.0281 & 0.9256 & 0.8351 & 1.874 & 1.985 & 2.037 & 2.082 & 74.96 & 79.43 & 81.48 & 83.30 \\
\hline 10 & 䓻 & 2.5780 & 2.2528 & 2.0281 & 1.9821 & 3.711 & 3.874 & 3.986 & 4.009 & 74.22 & 77.47 & 79.71 & 80.18 \\
\hline 15 & $\frac{\tilde{\sigma}}{\pi}$ & 4.7812 & 4.2121 & 4.0121 & 3.8559 & 5.109 & 5.394 & 5.494 & 5.572 & 68.13 & 71.92 & 73.25 & 74.29 \\
\hline 20 &.$\tilde{0}$ & 7.8521 & 7.2821 & 7.0421 & 6.8529 & 6.074 & 6.359 & 6.479 & 6.574 & 60.74 & 63.59 & 64.79 & 65.74 \\
\hline 25 & 㐫 & 11.2821 & 10.9251 & 10.4281 & 9.5790 & 6.859 & 7.037 & 7.286 & 7.711 & 54.87 & 56.30 & 58.29 & 61.68 \\
\hline 30 & U & 14.7281 & 14.2832 & 14.059 & 13.1512 & 7.636 & 7.858 & 7.971 & 8.424 & 50.81 & 52.39 & 53.14 & 56.16 \\
\hline 5 & ฮే & 0.5250 & 0.4578 & 0.4072 & 0.3875 & 2.2375 & 2.2711 & 2.2964 & 2.3062 & 89.50 & 90.84 & 91.85 & 92.25 \\
\hline 10 & 产 & 1.1250 & 1.0750 & 0.9852 & 0.7558 & 4.4380 & 4.4610 & 4.5074 & 4.6221 & 88.75 & 89.22 & 90.14 & 92.44 \\
\hline 15 & 离 & 1.8325 & 1.7240 & 1.5570 & 1.2541 & 6.5838 & 6.6350 & 6.7215 & 6.8729 & 87.78 & 88.50 & 89.62 & 91.63 \\
\hline 20 & $\frac{\tilde{0}}{\infty}$ & 2.7876 & 2.5494 & 2.2542 & 2.0490 & 8.6062 & 8.7254 & 8.8729 & 8.9755 & 86.06 & 87.25 & 88.72 & 89.75 \\
\hline 25 & $\stackrel{\bar{O}}{0}$ & 3.8980 & 3.7150 & 3.4715 & 3.1749 & 10.5510 & 10.6425 & 10.7642 & 10.9125 & 84.40 & 85.14 & 86.11 & 87.30 \\
\hline 30 & II & 5.8520 & 5.6852 & 5.2820 & 4.9957 & 12.0740 & 12.1574 & 12.3575 & 12.5021 & 80.40 & 81.04 & 82.38 & 83.34 \\
\hline
\end{tabular}




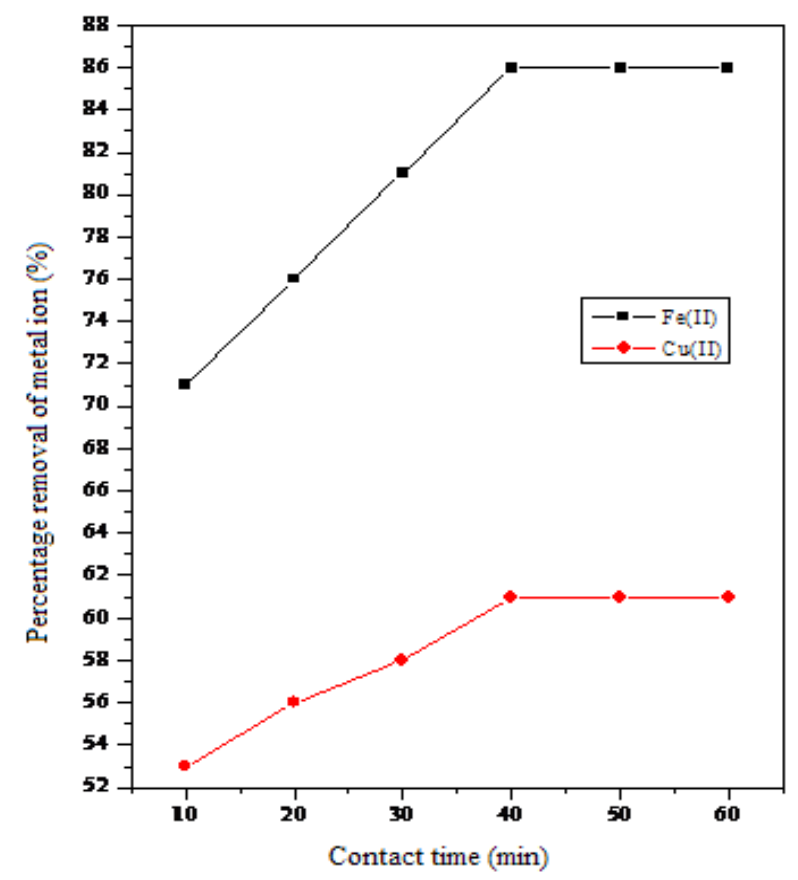

Figure 1. Effect of contact time on the removal of metal ions by PDC

\section{Effect of carbon concentration}

The adsorption of the metal ion on carbon was studied by varying the carbon concentration $(50-250 \mathrm{mg} / 50 \mathrm{~mL})$ for metal ion of $20 \mathrm{mg} / \mathrm{L}$. The percentage of adsorption increased with increase in the carbon concentration (Figure 2). This has attributed to increased carbon surface area and availability of more adsorption sites.

\section{Adsorption isotherm}

The experimental data are analyzed according to the linear form of the Langmuir and Freundlich isotherms. The Langmuir isotherm represented by the following equation ${ }^{6}$

$$
\mathrm{C}_{\mathrm{e}} / \mathrm{Q}_{\mathrm{e}}=1 / \mathrm{Q}_{\mathrm{m}} \mathrm{b}+\mathrm{C}_{\mathrm{e}} / \mathrm{Q}_{\mathrm{m}}
$$

Here $C_{e}$ is the equilibrium concentration $(\mathrm{mg} / \mathrm{L}), \mathrm{Q}_{\mathrm{e}}$ is the amount adsorbed at equilibrium $\left(\mathrm{mg} / \mathrm{g}\right.$ ) and $\mathrm{Q}_{\mathrm{m}}$ and $\mathrm{b}$ is Langmuir constants related to adsorption efficiency and energy of adsorption, respectively. The linear plots of $\mathrm{C}_{\mathrm{e}} / \mathrm{Q}_{\mathrm{e}}$ versus $\mathrm{C}_{\mathrm{e}}$ suggest the applicability of the Langmuir isotherms (Figure 3). The values of $\mathrm{Q}_{\mathrm{m}}$ and $\mathrm{b}$ were determined from slope and intercepts of the plots and are presented in Table 2. From the results, it is clear that the value of adsorption energy $b$ of the carbon increases on increasing the temperature. From the values of adsorption efficiency $\mathrm{Q}_{\mathrm{m}}$ we can conclude that the maximum adsorption corresponds to a saturated monolayer of adsorbate molecules on adsorbent surface with constant energy and no transmission of adsorbate in the plane of the adsorbent surface. The trend shows that the adsorbent prefers to bind acidic ions and that speciation predominates on sorbent characteristics, when ion exchange is the predominant mechanism. Further, it confirms the endothermic nature of the processes involved in the system. To confirm the favorability of the adsorption process, the separation factor $\left(\mathrm{R}_{\mathrm{L}}\right)$ is calculated and presented in Table 3. The values were found to be between 0 and 1 and confirm that the ongoing adsorption process is favourable ${ }^{7}$ 


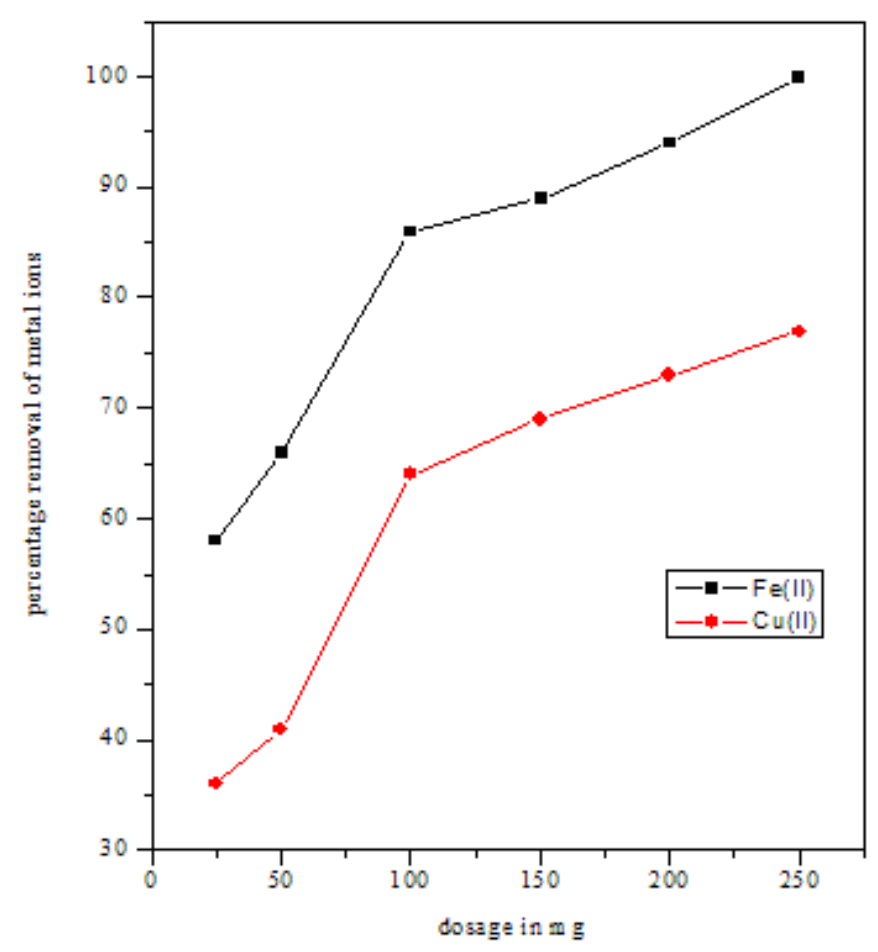

Figure 2. Effect of dosage on the removal of metal ions

Table 2. Langmuir isotherm results

\begin{tabular}{ccccc}
\hline Metal ion & Temp & \multicolumn{3}{c}{ Statistical Parameters/Constants } \\
\cline { 3 - 5 } & $\left({ }^{0} \mathrm{C}\right)$ & $\mathrm{r}^{2}$ & $\mathrm{Q}_{\mathrm{m}}$ & $\mathrm{b}$ \\
\hline Copper ion & 30 & 0.9968 & 10.0979 & 0.2008 \\
& 40 & 0.9976 & 9.7181 & 0.2707 \\
& 50 & 0.9986 & 9.6993 & 0.3089 \\
& 60 & 0.9987 & 10.4515 & 0.2926 \\
\hline Ferrous Ion & 30 & 0.9926 & 21.4915 & 0.2339 \\
& 40 & 0.9946 & 20.2675 & 0.2792 \\
& 50 & 0.9936 & 20.0680 & 0.3196 \\
& 60 & 0.9917 & 18.9286 & 0.4144 \\
\hline
\end{tabular}

The Freundlich equation have also employed for the adsorption of metal ions on the adsorbent. The Freundlich isotherm ${ }^{8}$ have represented as

$$
\log \mathrm{Q}_{\mathrm{e}}=\log \mathrm{K}_{\mathrm{f}}+1 / \mathrm{n} \log \mathrm{C}_{\mathrm{e}}
$$

Where $Q_{e}$ is the amount of metal ion adsorbed $(\mathrm{mg} / \mathrm{g}), \mathrm{C}_{\mathrm{e}}$ is the equilibrium concentration of metal ion in solution $(\mathrm{mg} / \mathrm{L})$ and $\mathrm{K}_{\mathrm{f}}$ and $\mathrm{n}$ are constants incorporating all factors affecting the adsorption capacity and intensity of adsorption, respectively. Linear plot of $\log Q_{\mathrm{e}}$ versus $\log \mathrm{C}_{\mathrm{e}}$ shows that the adsorption of metal ion follows the Freundlich 
isotherm (Figure 4). The values of $\mathrm{K}_{\mathrm{f}}$ and $\mathrm{n}$ were found and given in the Table 4, shows the increase of negative charge on the surface that enhances the electrostatic force like Vander waal's between the carbon surface and metal ions, which increases the adsorption of metal ions. The values clearly show that dominance in adsorption capacity. The intensity of adsorption is an indicative of the bond energies between metal ions and adsorbent and the possibility of slight chemisorptions rather than physisorption. The possibility of multilayer adsorption of metal ion through the percolation process cannot be ruled out. However, the values of $\mathrm{n}$ is greater than one indicating the adsorption is much more favourable $\mathrm{e}^{5,9}$

Table 3 - Dimensionless Separation factor $\left(\mathrm{R}_{\mathrm{L}}\right)$

\begin{tabular}{|c|c|c|c|c|}
\hline \multirow{2}{*}{$\begin{array}{c}{[\mathrm{M}]_{0}} \\
(\mathrm{mg} / \mathrm{L})\end{array}$} & \multicolumn{4}{|c|}{ Temperature, $\left({ }^{0} \mathrm{C}\right)$} \\
\hline & 30 & 40 & 50 & 60 \\
\hline 5 & 0.5000 & 0.4255 & 0.3923 & 0.4081 \\
\hline 10 & 0.3333 & 0.2702 & 0.2439 & 0.2565 \\
\hline 15 & 0.2500 & 0.1980 & 0.1769 & 0.1869 \\
\hline 20 & 0.2000 & 0.1562 & 0.1388 & 0.1470 \\
\hline 25 & 0.1666 & 0.1290 & 0.1144 & 0.1212 \\
\hline 30 & 0.1428 & 0.1098 & 0.0970 & 0.1030 \\
\hline 5 & 0.4609 & 0.4166 & 0.3846 & 0.3257 \\
\hline 10 & 0.2994 & 0.2631 & 0.2380 & 0.1945 \\
\hline 15 & 0.2222 & 0.1923 & 0.1724 & 0.1386 \\
\hline 20 & 0.1763 & 0.1519 & 0.1351 & 0.1077 \\
\hline 25 & 0.1461 & 0.1254 & 0.1111 & 0.0881 \\
\hline 30 & 0.1248 & 0.1067 & 0.0943 & 0.0745 \\
\hline \multicolumn{5}{|c|}{ Table 4 - Freundlich isotherm results } \\
\hline \multirow[t]{2}{*}{ Metal ion } & \multirow{2}{*}{$\begin{array}{c}\text { Temp } \\
\left({ }^{0} \mathrm{C}\right)\end{array}$} & \multicolumn{3}{|c|}{ Statistical parameters / constants } \\
\hline & & $r^{2}$ & $\mathrm{~K}_{\mathrm{f}}$ & $\mathrm{n}$ \\
\hline \multirow[t]{4}{*}{ Copper ion } & 30 & 0.9753 & 1.3366 & 1.8587 \\
\hline & 40 & 0.9715 & 1.4328 & 2.0169 \\
\hline & 50 & 0.9712 & 1.4837 & 2.0955 \\
\hline & 60 & 0.9830 & 1.5059 & 2.0325 \\
\hline \multirow[t]{4}{*}{ Ferrous Ion } & 30 & 0.9894 & 1.8047 & 1.4074 \\
\hline & 40 & 0.9900 & 1.8648 & 1.4560 \\
\hline & 50 & 0.9887 & 1.9340 & 1.4764 \\
\hline & 60 & 0.9762 & 2.0301 & 1.5304 \\
\hline
\end{tabular}




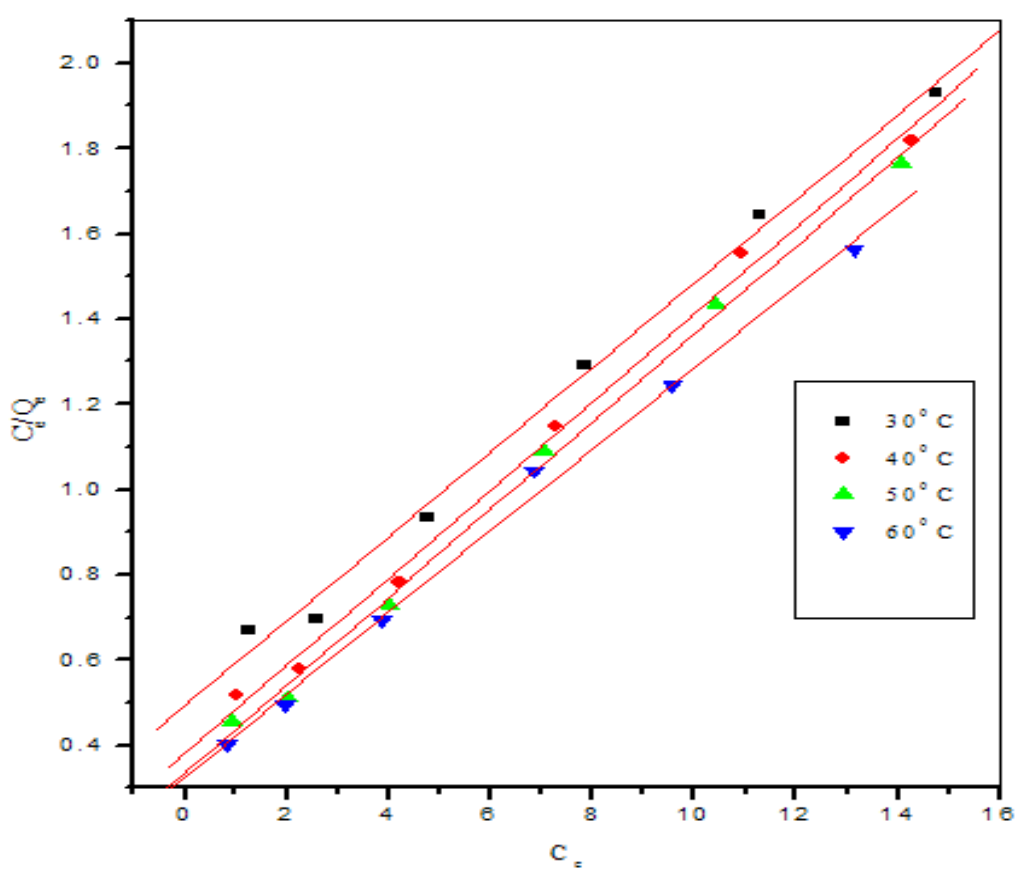

Figure 3. Langmuir isotherm for the adsorption of copper ion onto PDC

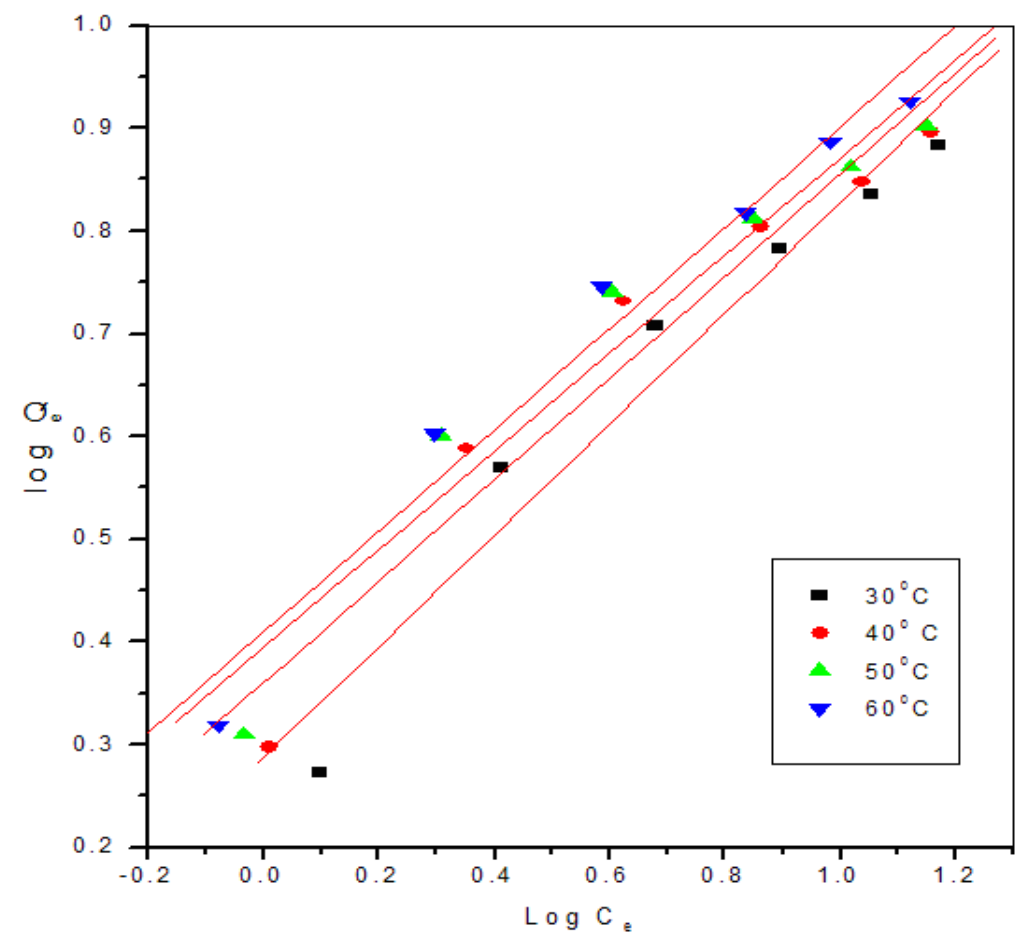

Figure 4. Freundlich isotherm for the adsorption of copper ion onto PDC 


\section{Kinetics of adsorption}

The kinetics of sorption describes the solute uptake rate, which in turn governs the residence time of sorption reaction. It is one of the important characteristics in defining the efficiency of sorption. In the present study, the kinetics of the metal ion removal has carried out to understand the behaviour of this low cost carbon adsorbent. The adsorption of metal ions from an aqueous solution follows reversible first order kinetics, when a single species considered on a heterogeneous surface. The heterogeneous equilibrium between the metal ion solutions and the activated carbon have expressed as

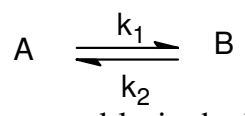

Here $\mathrm{k}_{1}$ is the forward rate constant and $\mathrm{k}_{2}$ is the backward rate constant. A represents metal ion remaining in the aqueous solution and $\mathrm{B}$ represents metal ion adsorbed on the surface of activated carbon. The rate constants calculated as earlier ${ }^{10,11}$. The data furnished in Table 6, shows that the forward rate constant is much higher than the backward rate constant suggesting that the rate of adsorption is clearly dominant. At equilibrium, the rate is the ratio of the concentration of adsorbate in adsorbent and concentration of adsorbate in aqueous solution is given by $\mathrm{K}_{0}$. The results shown in Table 5 indicates that $\mathrm{K}_{0}$ values decreases with increase in the concentration of the metal ions and increases with increase in temperature. Examination of the effect of metal ion concentrations on the rate constant $\mathrm{K}_{\mathrm{ad}}$ (Table 6), the values help to describe the mechanism of metal ion removal taking place ${ }^{11}$.In cases of strict surface adsorption a variation of rate should be proportional to the first power of concentration. However, when pore diffusion limits the adsorption process, the relationship between initial metal ion concentration and rate of reaction will not be linear ${ }^{10}$

\section{Effect of temperature}

The adsorption capacity of the carbon increased with increase in the temperature of the system from $30-60{ }^{\circ} \mathrm{C}$. Thermodynamic parameters such as change in free energy $\left(\Delta \mathrm{G}^{\circ}\right) \mathrm{kJ} / \mathrm{mol}$, enthalpy $\left(\Delta \mathrm{H}^{\circ}\right)$ $\mathrm{kJ} / \mathrm{mol}$ and entropy $\left(\Delta \mathrm{S}^{\circ}\right) \mathrm{J} / \mathrm{K} / \mathrm{mol}$ were determined using the following equations ${ }^{12,13}$

$$
\begin{aligned}
& \mathrm{K}_{0}=\mathrm{C}_{\text {solid }} / \mathrm{C}_{\text {liquid }} \\
& \Delta \mathrm{G}^{\circ}=-\mathrm{RT} \ln \mathrm{K}_{\mathrm{O}} \\
& \operatorname{Iog} \mathrm{K}_{0}=\Delta \mathrm{S}^{\circ} /(2.303 \mathrm{RT})-\Delta \mathrm{H}^{\circ} /(2.303 \mathrm{RT})
\end{aligned}
$$

Here $\mathrm{Ko}$ is the equilibrium constant, $\mathrm{C}_{\text {solid }}$ is the solid phase concentration at equilibrium $(\mathrm{mg} / \mathrm{L}), \mathrm{C}_{\text {liquid }}$ is the liquid phase concentration at equilibrium $(\mathrm{mg} / \mathrm{L}), \mathrm{T}$ is the temperature in Kelvin and $\mathrm{R}$ is the gas constant. The $\Delta \mathrm{H}^{\circ}$ and $\Delta \mathrm{S}^{\circ}$ values obtained from the slope and intercept of Van't Hoff plots have presented in Table 5. The values are with in the range of 1 to $93 \mathrm{KJ} / \mathrm{mol}$ indicates the favourability of physisorption. From the order we could conclude that physisorption is much more favourable for metal ions. The positive values of $\Delta \mathrm{H}^{\circ}$ show the endothermic nature of adsorption and it governs the possibility of physical adsorption ${ }^{14}$. In the case of physical adsorption, while increasing the temperature of the system, the extent of metal ion adsorption increases, this rules out the possibility of chemisorptions. However, the very low $\Delta \mathrm{H}^{\circ}$ value depicts metal ions are physisorbed onto adsorbent ${ }^{15,16}$

The negative values of $\Delta \mathrm{G}^{\circ}$ (Table 5) shows that the adsorption is highly favourable for metal ions. However, it indicates that the metal ion adsorption is spontaneous. The positive values of $\Delta S^{\circ}$ (Table 5) shows the increased disorder and randomness at the solid solution interface of the adsorbent. During adsorption there are some structural changes in the metal ion and the adsorbent occur ${ }^{17}$. From the results, we could make out that more efficient physisorption. Enhancement of adsorption capacity of the activated carbon at higher temperatures is attributed to the enlargement of pore size and activation of the adsorbent surface ${ }^{4}$. 
Table 5. Equilibrium constant and thermodynamic parameters for the adsorption of metal ions onto PD carbon

\begin{tabular}{|c|c|c|c|c|c|c|c|c|c|c|c|}
\hline \multirow[t]{2}{*}[\mathrm{M}]{$_{0}$} & & \multicolumn{4}{|c|}{$\mathrm{K}_{0}$} & \multicolumn{4}{|c|}{$\Delta \mathrm{G}^{\mathrm{o}}$} & \multirow{2}{*}{$\Delta \mathrm{H}^{\mathrm{o}}$} & \multirow{2}{*}{$\Delta S^{o}$} \\
\hline & & $30^{\circ} \mathrm{C}$ & $40^{\circ} \mathrm{C}$ & $50^{\circ} \mathrm{C}$ & $60^{\circ} \mathrm{C}$ & $30^{\circ} \mathrm{C}$ & $40^{\circ} \mathrm{C}$ & $50^{\circ} \mathrm{C}$ & $60^{\circ} \mathrm{C}$ & & \\
\hline 5 & \multirow{6}{*}{ 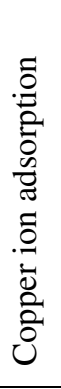 } & 2.9936 & 3.8633 & 4.4019 & 4.9873 & -2.761 & -3.517 & -3.979 & -4.445 & 13.895 & 55.21 \\
\hline 10 & & 2.8789 & 3.4389 & 3.9309 & 4.0451 & -2.663 & -3.213 & 3.675 & -3.867 & 9.709 & 41.05 \\
\hline 15 & & 2.1372 & 2.5611 & 2.7386 & 2.8901 & -1.913 & -2.446 & -2.704 & -2.937 & 8.170 & 33.52 \\
\hline 20 & & 1.5470 & 1.7464 & 1.8399 & 1.9184 & -1.098 & -1.449 & -1.635 & -1.803 & 5.855 & 23.10 \\
\hline 25 & & 1.2158 & 1.2883 & 1.3973 & 1.6098 & -0.491 & -0.659 & -0.896 & -1.317 & 7.591 & 26.49 \\
\hline 30 & & 1.0369 & 1.1003 & 1.1338 & 1.2811 & -0.091 & -0.247 & -0.335 & -0.683 & 5.461 & 18.22 \\
\hline 5 & \multirow{6}{*}{$\begin{array}{l}\tilde{0} \\
.0 \\
0 \\
0 \\
0 \\
0 \\
0 \\
\tilde{0} \\
.0 \\
0 \\
0 \\
0 \\
0 \\
0 \\
\text { I }\end{array}$} & 8.823 & 9.5495 & 11.2789 & 11.9032 & -5.397 & -5.871 & -6.503 & -6.854 & 8.215 & 49.935 \\
\hline 10 & & 7.888 & 8.2764 & 9.1502 & 12.2307 & -5.201 & -5.498 & -5.943 & -6.938 & 11.547 & 54.807 \\
\hline 15 & & 7.1855 & 7.7006 & 8.6339 & 10.9616 & -4.967 & -5.310 & -5.787 & -6.627 & 11.319 & 53.398 \\
\hline 20 & & 6.1746 & 6.8455 & 7.8723 & 8.7608 & -4.585 & -5.003 & -5.539 & -6.006 & 9.872 & 13.182 \\
\hline 25 & & 5.4135 & 5.7294 & 6.2006 & 6.8761 & -4.252 & -4.540 & -4.898 & -5.336 & 6.569 & 35.598 \\
\hline 30 & & 4.1264 & 4.2768 & 4.6796 & 5.0051 & -3.569 & -3.782 & -4.142 & -4.457 & 5.528 & 29.907 \\
\hline
\end{tabular}


Table 6. Rate constants for the adsorption of metal ions $\left(10^{3} \mathrm{k}_{\mathrm{ad}}\right.$, $\left.\min ^{-1}\right)$ and the constants for forward $\left(10^{3} \mathrm{k}_{1}\right.$, $\left.\min ^{-1}\right)$ and reverse $\left(10^{3} \mathrm{k}_{2}, \mathrm{~min}^{-1}\right)$ process.

\begin{tabular}{|c|c|c|c|c|c|c|c|c|c|c|c|c|c|}
\hline \multirow{2}{*}{$\mathrm{M}_{0}$} & & \multicolumn{4}{|c|}{$\mathrm{k}_{\mathrm{ad}}$} & \multicolumn{2}{|c|}{$30^{\circ} \mathrm{C}$} & \multicolumn{2}{|c|}{$40^{\circ} \mathrm{C}$} & \multicolumn{2}{|c|}{$50^{\circ} \mathrm{C}$} & \multicolumn{2}{|c|}{$60^{\circ} \mathrm{C}$} \\
\hline & & $30^{\circ} \mathrm{C}$ & $40^{\circ} \mathrm{C}$ & $50^{\circ} \mathrm{C}$ & $60^{\circ} \mathrm{C}$ & $\mathrm{k}_{1}$ & $\mathrm{k}_{2}$ & $\mathrm{k}_{1}$ & $\mathrm{k}_{2}$ & $\mathrm{k}_{1}$ & $\mathrm{k}_{2}$ & $\mathrm{k}_{1}$ & $\mathrm{k}_{2}$ \\
\hline 5 & $\approx$ & 13.270 & 15.770 & 14.891 & 17.680 & 9.9472 & 3.3228 & 12.5274 & 3.2436 & 12.130 & 2.7564 & 14.727 & 2.9530 \\
\hline 10 & 冡 & 10.508 & 11.639 & 1.881 & 12.521 & 7.7931 & 2.7069 & 8.9960 & 2.6340 & 9.471 & 2.4097 & 10.039 & 2.4816 \\
\hline 15 & 总 & 7.3903 & 7.738 & 10.913 & 9.492 & 5.0346 & 2.3557 & 5.5651 & 2.1729 & 7.992 & 2.9186 & 7.052 & 2.4403 \\
\hline 20 & 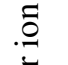 & 5.9878 & 6.476 & 7.024 & 6.694 & 3.6369 & 2.3509 & 4.1181 & 2.3579 & 4.551 & 2.4733 & 4.404 & 2.2943 \\
\hline 25 & $\begin{array}{l}\overline{0} \\
\overline{2}\end{array}$ & 8.1226 & 8.177 & 8.705 & 9.142 & 4.4569 & 3.6657 & 4.6042 & 3.5737 & 5.074 & 3.6311 & 5.639 & 3.5032 \\
\hline 30 & 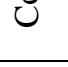 & 6.4253 & 6.722 & 6.766 & 7.339 & 3.2695 & 3.1518 & 3.5221 & 3.2006 & 3.595 & 3.1709 & 4.122 & 3.2175 \\
\hline 5 & ๘ี & 4.5737 & 3.7568 & 3.4545 & 2.8780 & 4.0935 & 0.4802 & 3.3980 & 0.3558 & 3.1732 & 0.2813 & 2.6550 & 0.2230 \\
\hline 10 & 蒙 & 27.935 & 25.7930 & 20.3664 & 4.3200 & 24.7920 & 3.1430 & 23.0192 & 2.7738 & 18.2424 & 1.9936 & 3.9930 & 0.3265 \\
\hline 15 & 离 & 26.046 & 24.4110 & 23.2830 & 22.2460 & 22.8641 & 3.1821 & 21.6053 & 2.8057 & 20.8660 & 2.4170 & 20.3860 & 1.8600 \\
\hline 20 &.$\frac{\tilde{\sigma}}{\infty}$ & 24.365 & 25.5860 & 24.3420 & 21.5300 & 20.9130 & 3.3962 & 22.3248 & 3.2614 & 21.5977 & 2.7443 & 19.3300 & 2.2089 \\
\hline 25 & $\stackrel{0}{0}$ & 22.138 & 21.5260 & 16.6960 & 14.3840 & 18.8686 & 3.4521 & 18.3271 & 3.1989 & 14.3772 & 2.3188 & 12.5580 & 1.8263 \\
\hline 30 & & 21.222 & 19.6960 & 16.1348 & 13.7300 & 17.0800 & 4.1400 & 18.9581 & 3.7319 & 13.2939 & 2.8409 & 11.4440 & 2.2864 \\
\hline
\end{tabular}




\section{Effect of $p H$}

The experiments carried out at different $\mathrm{pH}$ shows that there was a change in the percent removal of metal ions over the entire $\mathrm{pH}$ range of 3 to 9 shown in the Figure 5. This indicates the strong force of interaction between the metal ion and the activated carbon that, either $\mathrm{H}^{+}$or $\mathrm{OH}^{-}$ions could influence the adsorption capacity. Here the interaction is more at $\mathrm{pH} 6$, due to the competence of acidic $\mathrm{H}^{+}$ion with metal cation for the sorption sites. The percentage of sorption increased at the above $\mathrm{pH}$ value is due to the presence of ionic $\mathrm{COOH}$ groups. The adsorption of metal ions on the activated carbon does involve ion exchange mechanism. The adsorption of metal ions through ion exchange mechanism due to that there should be an influence on the metal ion adsorption while varying the $\mathrm{pH}^{18}$.

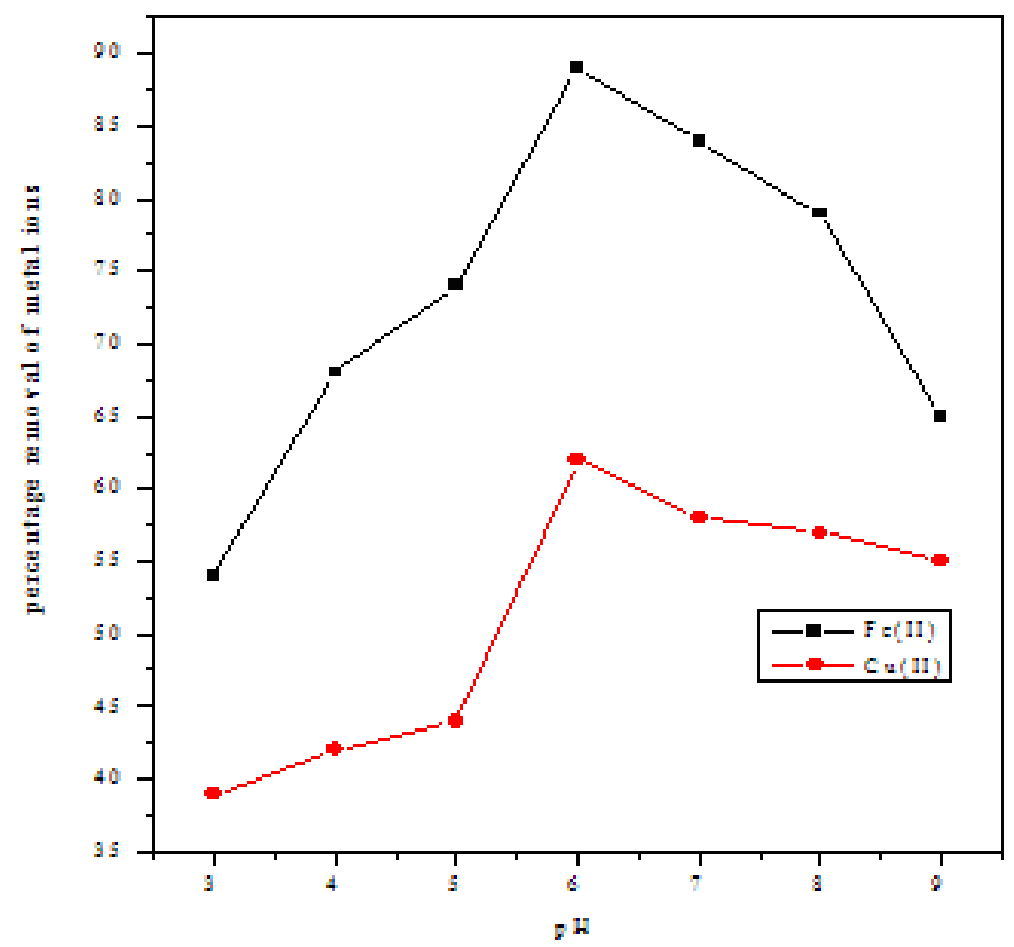

Figure 5. Effect of $\mathrm{pH}$ on the removal of metal ion

\section{Effect of other ions}

The effect of other ions like $\mathrm{Ca}^{2+}$ and $\mathrm{Cl}^{-}$on the adsorption process studied at different concentrations. The ions added to $20 \mathrm{mg} / \mathrm{L}$ of metal ion solutions and the contents were agitated for $60 \mathrm{~min}$ at $30 \mathrm{C}$. The results had shown in the Figure 6 and 7 reveals that low concentration of $\mathrm{Cl}^{-}$does not affect the percentage of adsorption of metal ion on activated carbon, because the interaction of $\mathrm{Cl}^{-}$at available sites of adsorbent through competitive adsorption is not so effective. While the concentration of other ion $\mathrm{Ca}^{2+}$ increases, the interference of these ions at available surface sites of the sorbent through competitive adsorption increases that, decreases the percentage adsorption. The interference was more in the presence of $\mathrm{Ca}^{2+}$ compared with $\mathrm{Cl}^{-}$ion. This is so because ions with smaller hydrated radii decrease the swelling pressure with in the sorbent and increase the affinity of the sorbent for such ions ${ }^{5,19}$ 


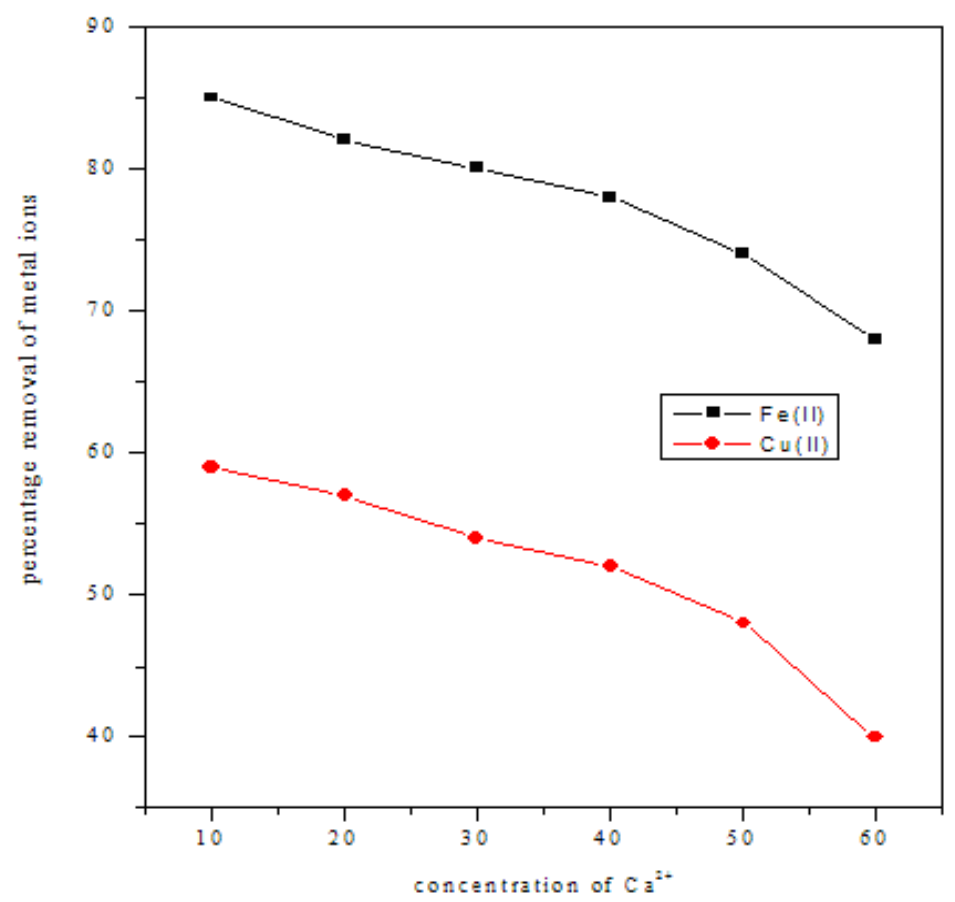

Figure 6. Effect of $\mathrm{Ca}^{2+}$ on the removal of metal ion

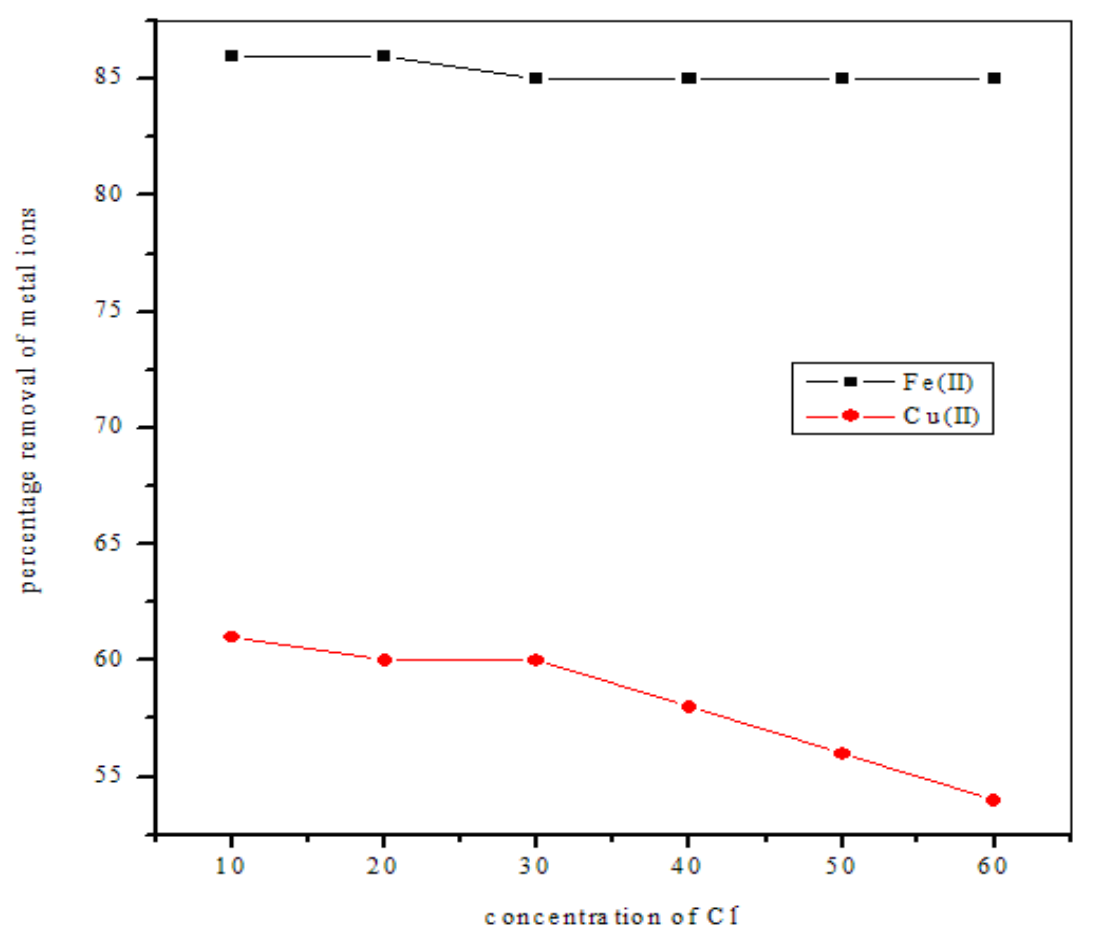

Figure 7. Effect of $\mathrm{Cl}^{-}$on the removal of metal ion 


\section{Desorption studies}

Desorption studies help to elucidate the nature of adsorption and recycling of the spent adsorbent and the metal ions. If the adsorbed metal ions can be desorbed using neutral $\mathrm{pH}$ water, then the attachment of the metal ion of the adsorbent is by weak bonds. Sulphuric acid or alkaline water desorp the metal ions then the adsorption is by ion exchange $\mathrm{e}^{20}$. The effect of various reagents used for desorption studies is shown in Figure 8. The results indicate that hydrochloric acid is a better reagent for desorption, because we could get more than $90 \%$ removal of adsorbed metal ion. The reversibility of adsorbed metal ion in mineral acid or base is in agreement with the $\mathrm{pH}$ dependent results obtained. The desorption of metal ion by mineral acids and alkaline medium indicates that the metal ion was adsorbed onto the activated carbon through by physisorption ${ }^{21}$

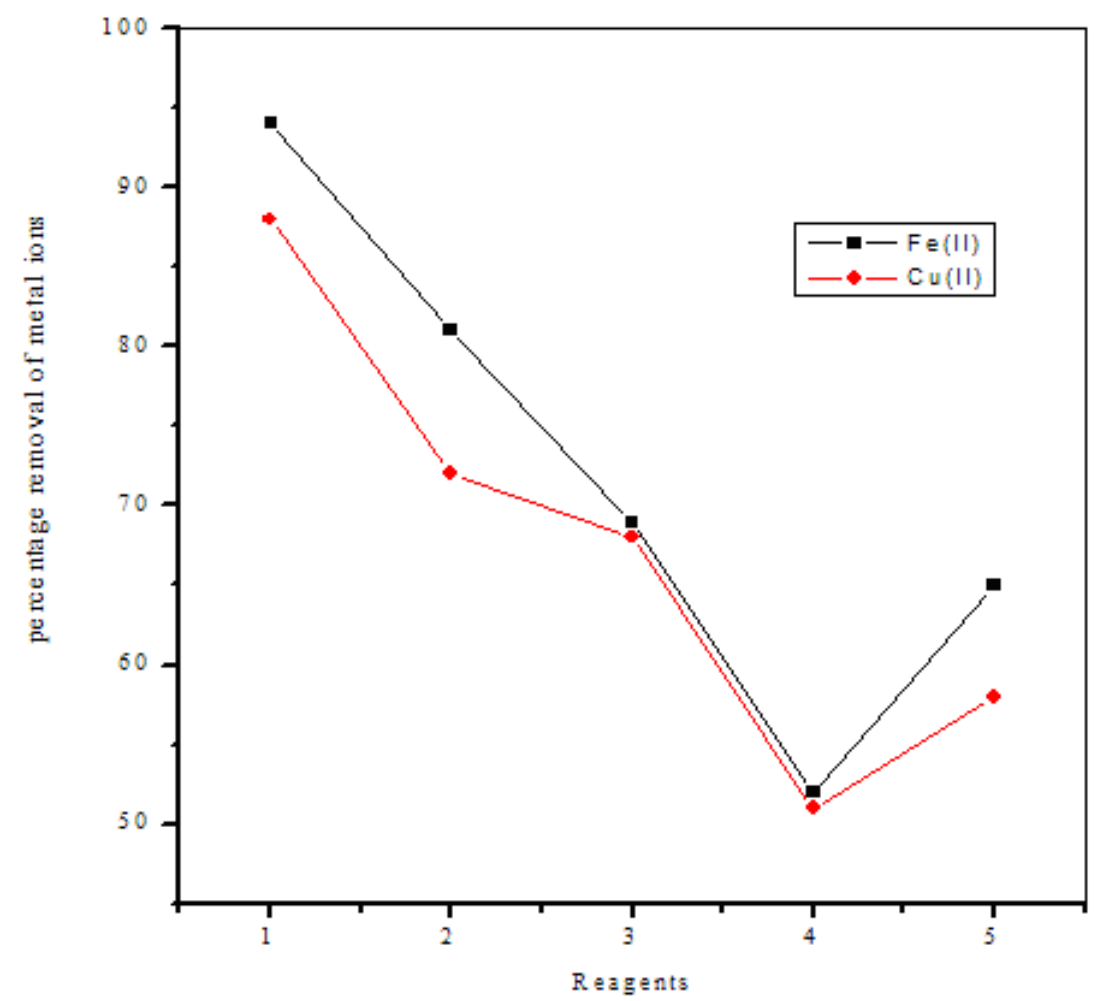

Figure 8. Regeneration pattern (1- $\left.\mathrm{HCl}, 2-\mathrm{HNO}_{3}, 3-\mathrm{H}_{2} \mathrm{SO}_{4}, 4-\mathrm{NaCl}, 5-\mathrm{NaCl}+\mathrm{H}_{2} \mathrm{O}\right)$

\section{Evidences for adsorption}

The IR spectra of the raw activated carbon and after adsorption of metal ions have shown in representative Figs. 9 and 10. It could be seen that the slight reduction of stretching vibration adsorption bands. This clearly indicates the adsorption of metal ion on the adsorbent by physical forces not by chemical combination. The XRD diagrams of activated carbon and metal ions-adsorbed carbon have shown in representative Figs. 11 and 12. The intense main peak shows the presence of highly organized crystalline structure of raw activated carbon ${ }^{22}$, after the adsorption of metal ion, the intensity of the highly organized peaks are slightly diminished. This has attributed to the adsorption of metal ions on the 
upper layer of the crystalline structure of the carbon surface by means of physisorption. The SEM diagrams of raw activated carbon and metal ions-adsorbed activated carbon have shown in representative Figure 13 and 14. The bright spots, shows the presence of tiny holes on the crystalline structure of raw activated carbon, after treatment with metal ions the bright spots became black shows the adsorption of the metal ions on the surface of the carbon.

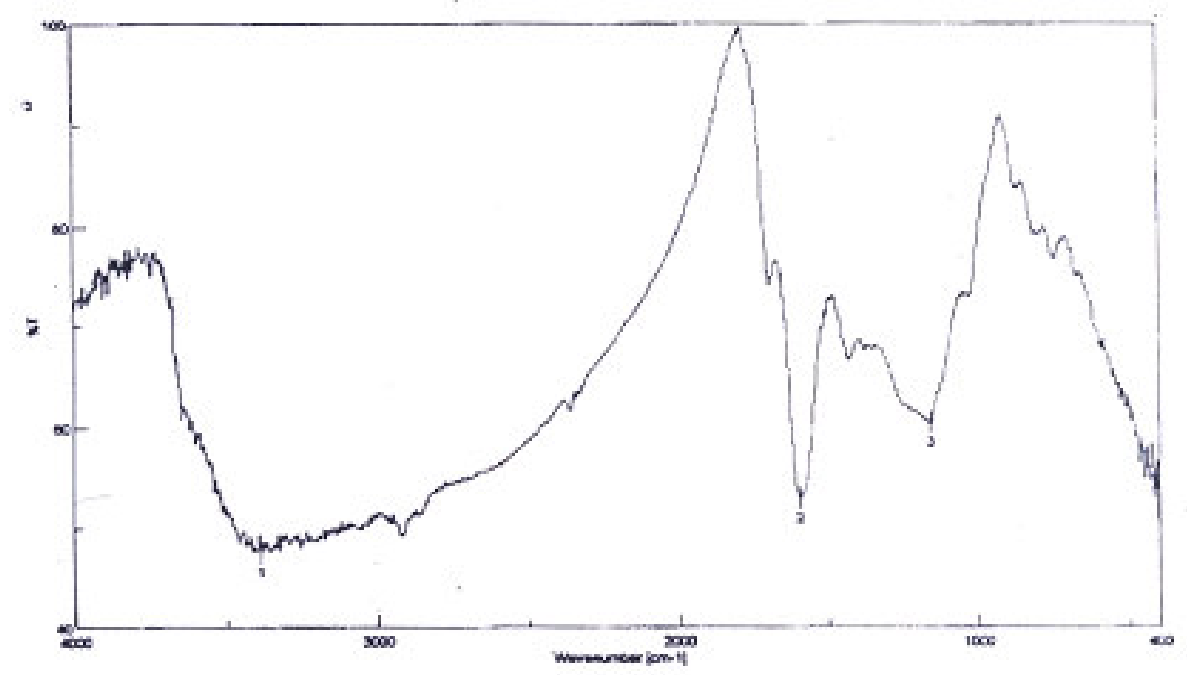

Figure 9. FT-IR Spectrum of absorbent before absorption

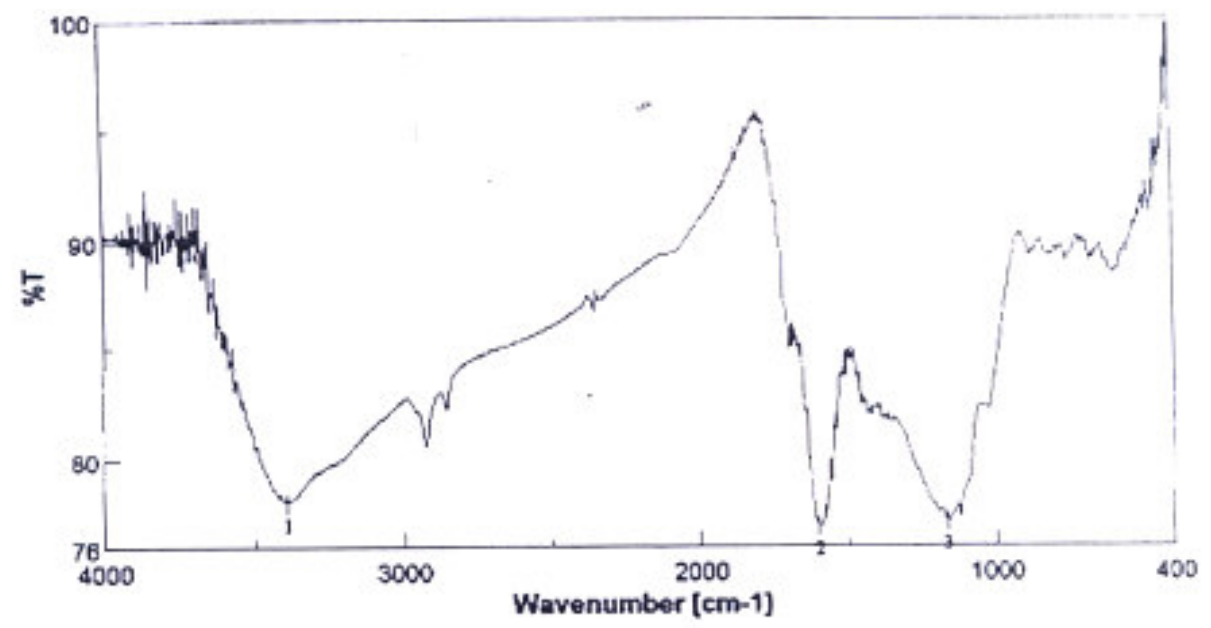

Figure 10. FT-IR Spectrum of absorbent after absorption 


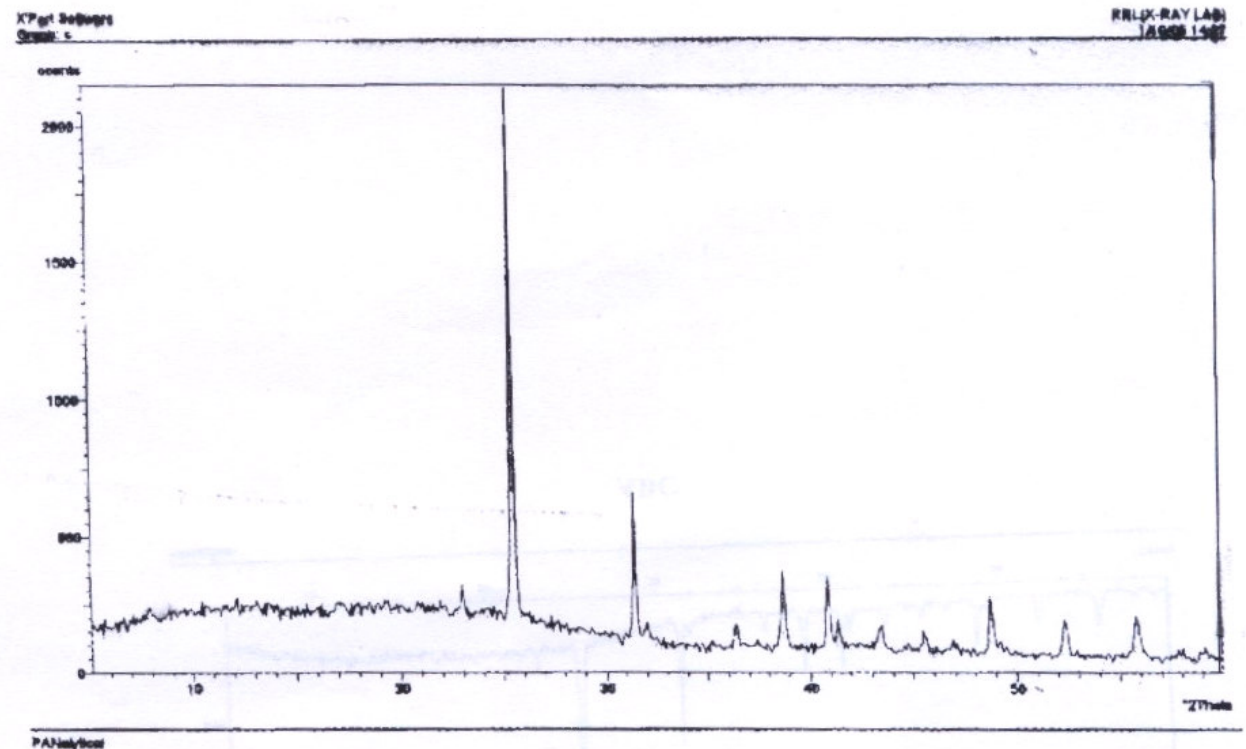

Figure 11. XRD pattern of the adsorbent before adsorption

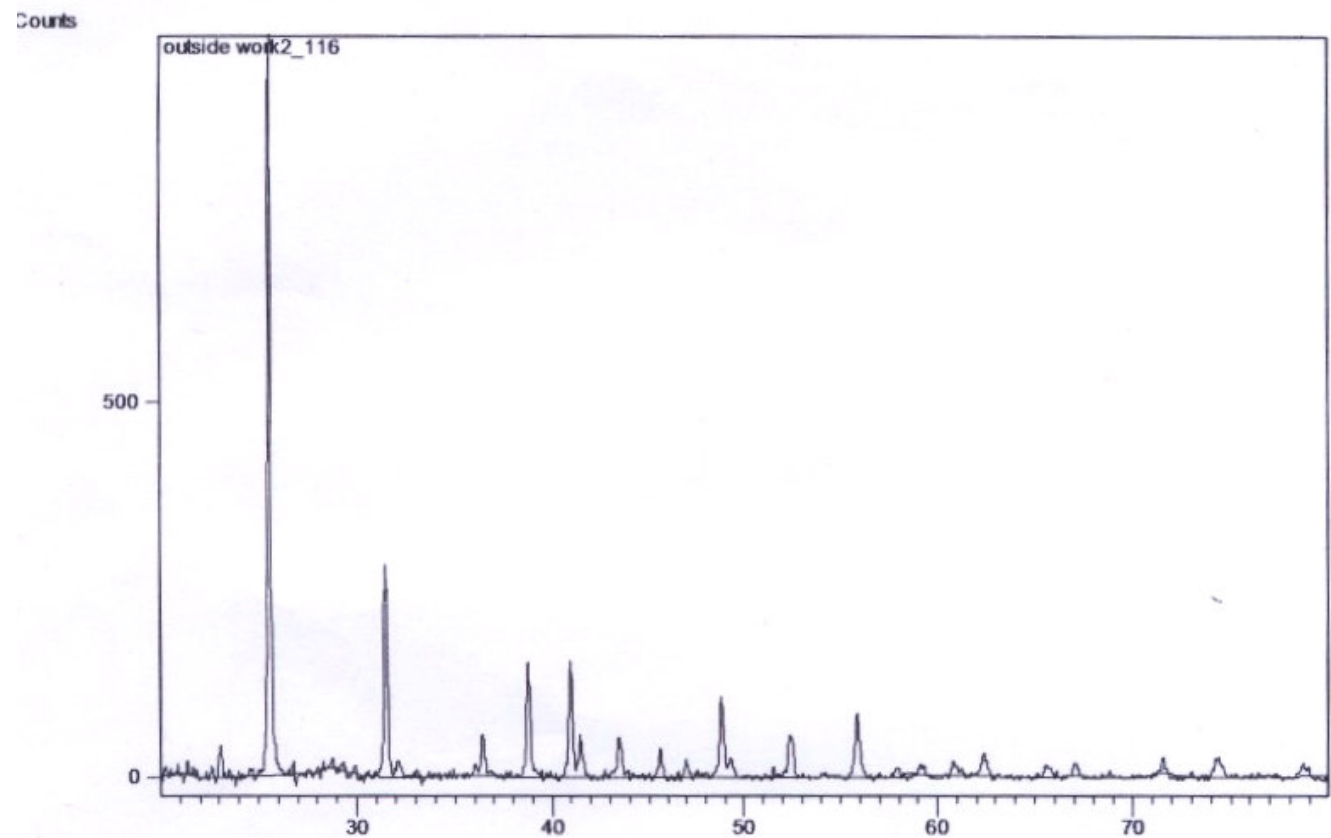

Figure 12.XRD pattern of the adsorbent after adsorption 


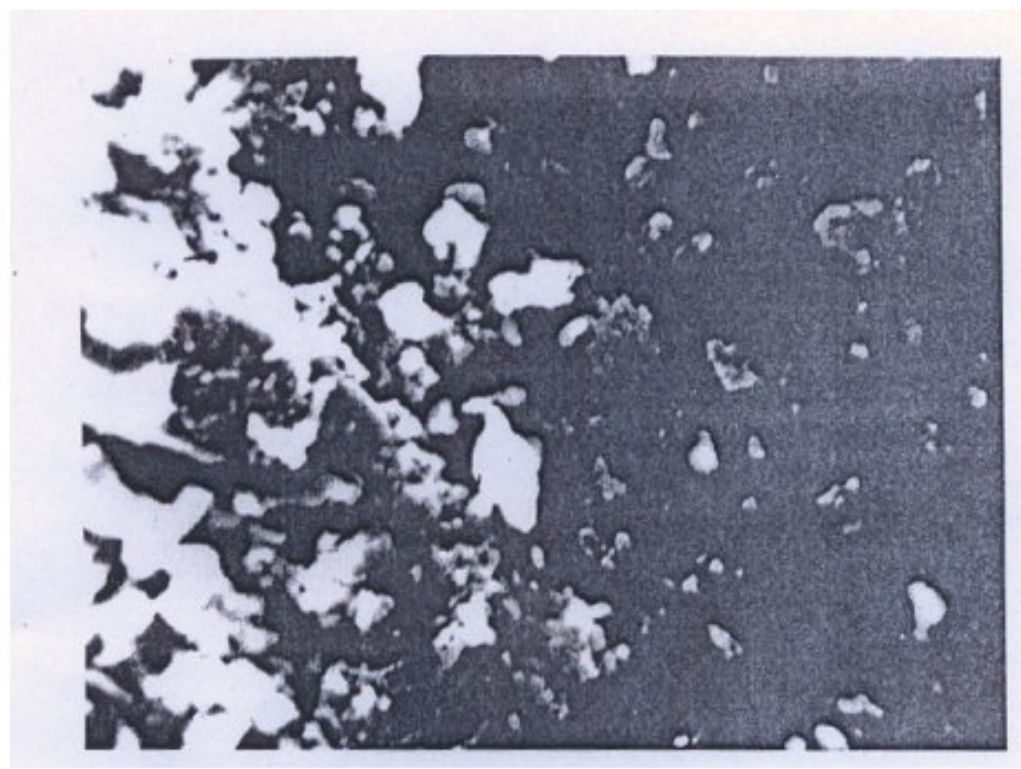

Figure 13. SEM image of absorbent before absorption

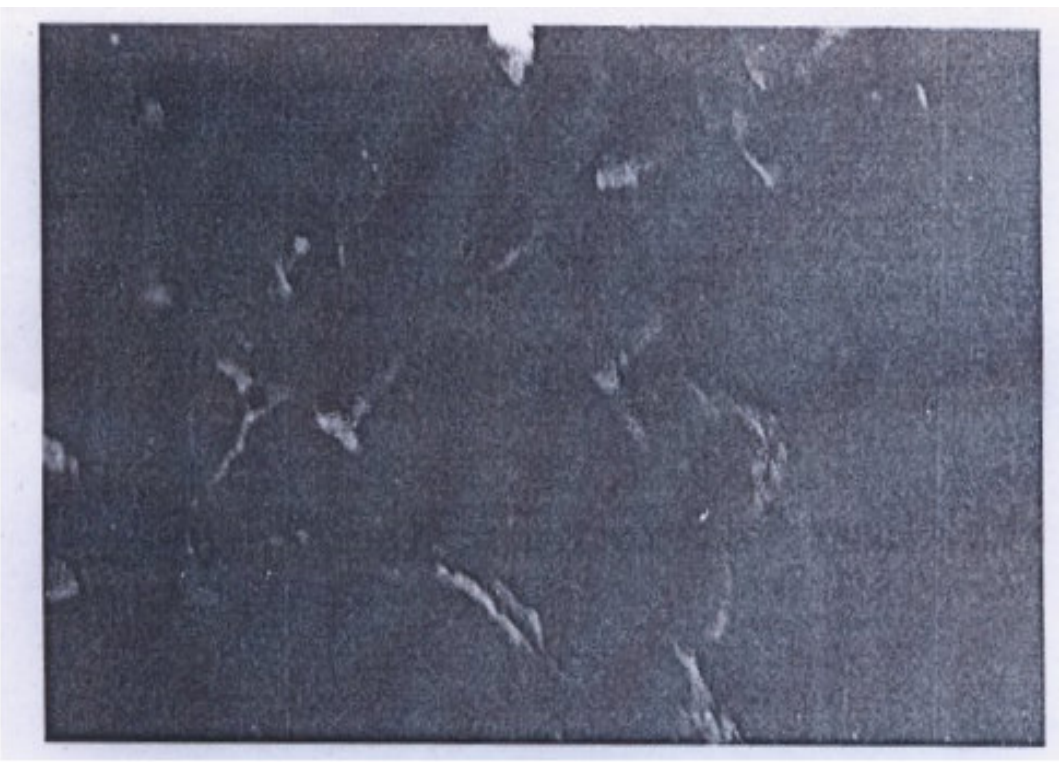

Figure 14. SEM image of absorbent before absorption

\section{Conclusions}

The experimental data correlated reasonably well by the Langmuir and Freundlich adsorption isotherms and the isotherm parameters were calculated. The amount of metal ions adsorbed increased with increase in $\mathrm{pH}$ of the medium. The amount of metal ion adsorbed slightly decreased with increasing ionic strength and increased with increase in temperature. 
The dimensionless separation factor $\left(\mathrm{R}_{\mathrm{L}}\right)$ showed that the activated carbon can be used for the removal of metal ions from aqueous solution. The values of $\Delta \mathrm{H}^{\circ}, \Delta \mathrm{S}^{\circ}$ and $\Delta \mathrm{G}^{\circ}$ results shows that the carbon employed has a considerable potential as an adsorbent for the removal of metal ions.

\section{Acknowledgements}

The authors acknowledge sincere thanks to Prof S. Ravi, Head, Department of Chemistry, The Principal, M.R. Government Arts College, Mannargudi and The Director of Collegiate Education, Chennai for carrying out this research work successfully. The authors dedicated this work to Mala Arivoli.

\section{References}

1. Weber E J and Stickney V C, Water Res, 1993, 27, 63

2. Sekaran G, Shanmugasundaram K A, Mariappan M and Raghavan K V, Indian J Chem Technol, 1995, 2, 311

3. Selvarani K, Studies on Low cost Adsorbents for the removal of Organic and Inorganics from Water $\mathrm{Ph}$ D., Thesis, Regional Engineering College, Tiruchirapalli, 2000

4. Senthikumar S, Varatharajan P R, Porkodi K, Subburaam C V, J Colloid Interface Sci, 2005, 284, 79.

5. Vadivelan V, Vasanthkumar K, J Colloid Interface Sci, 2005, 28691.

6. Langmuir I, J Amer Chem Soc, 1918, 40, 1361.

7. Khattri S D and Singh M K, Indian J Chem Technol,1999, 3, 114.

8. Freundlich H, Phys Chemie, 1906, 57, 384.

9. Aravind K Singh and Prem N Tiwari, Indian J Chem Technol, 2003, 10, 215.

10. Kocke W R and Hemphill L H, Res, 1981,15, 275.

11. Weber W J, Principle and Application of Water Chemistry, ed. by Faust S D and Hunter J V Wiley, New York, 1967.

12. Catena G C and Bright F V, Anal Chem, 1989, 61, 905.

13. Fraiji L K, Hayes D M and Werner T C, J Chem Edu, 1992, 69, 424.

14. McKay G, Blair H S and Gardner J R, J Appl Sci, 1982, 27, 3042.

15. McKay G, J Chem Tech Biotechnol, 1982, 32, 759.

16. McKay G and Poots V J P, J Chem Tech Biotechnol, 1980, 30, 279.

17. Namasivayam C and Yamuna R T, Environ Pollut, 1995, 89, 1.

18. Sivaraj R, Namasivayam C and Kadirvelu K, Waste Management, 2001, 21, 105.

19. Anuirudhan T S and Sreedhar M K, Indian J Environ Protect, 1999, 19, 8.

20. Namasivayam C, Muniasamy N, Gayatri K, Rani M and Ranganathan K, Biores Technol, 1996, 57, 37.

21. Krishna D G, Bhattacharyya G, Appl Clay Sci, 2002, 20, 295.

22. Renmin Gong, Yingzhi Sun, Jian Chen, Huijun Liu, Chao yang, Dyes and Pigments, 2005, 67, 179. 


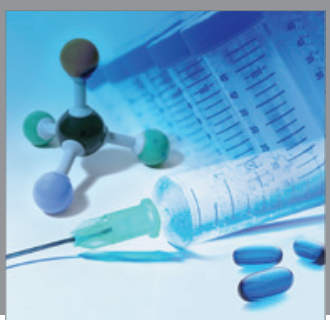

International Journal of

Medicinal Chemistry

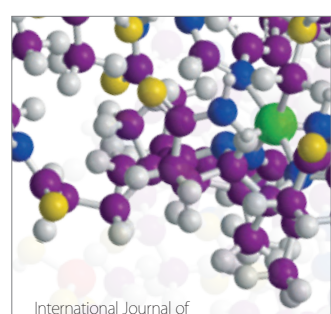

Carbohydrate Chemistry

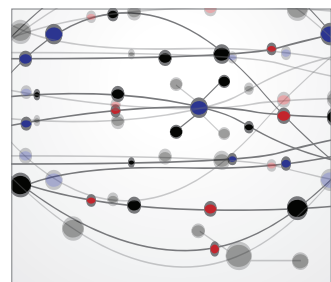

The Scientific World Journal
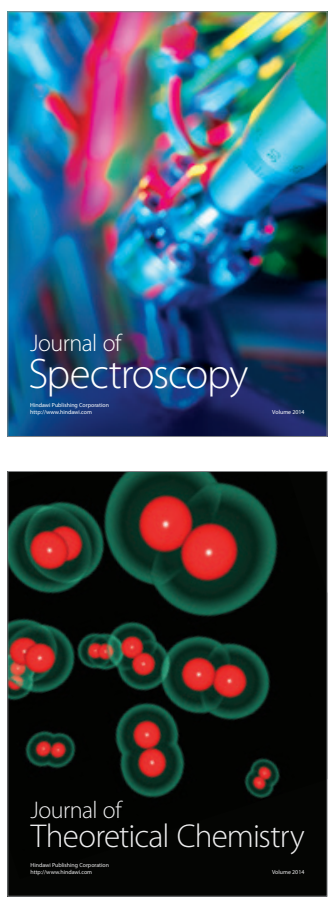
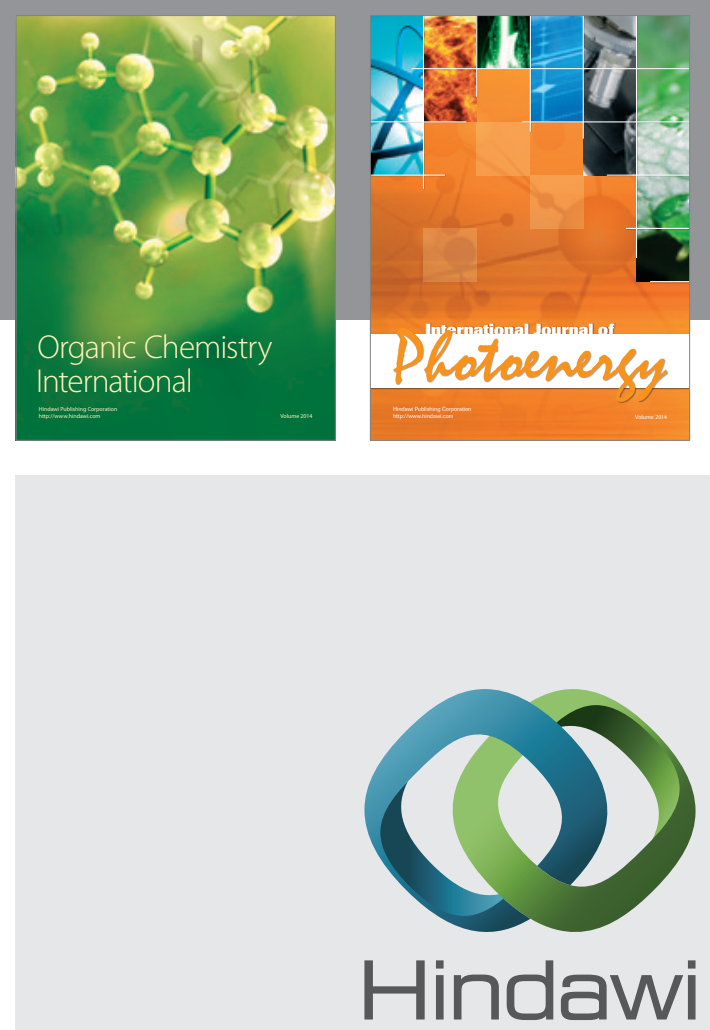

Submit your manuscripts at

http://www.hindawi.com
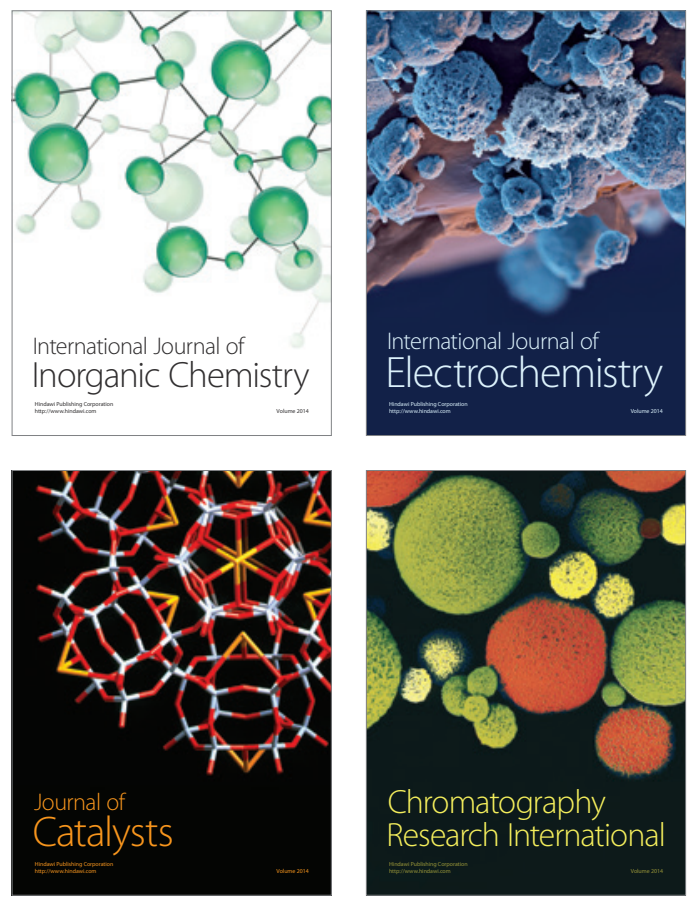
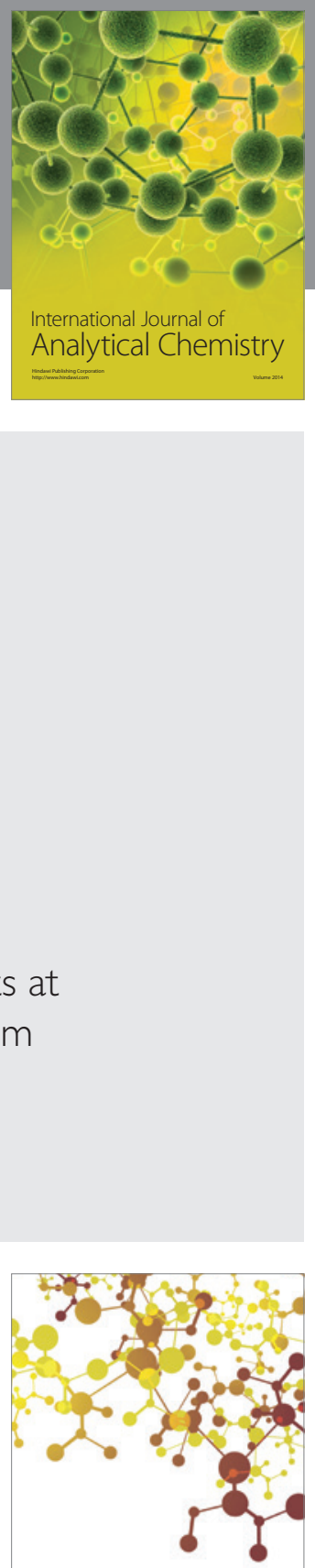

Journal of

Applied Chemistry
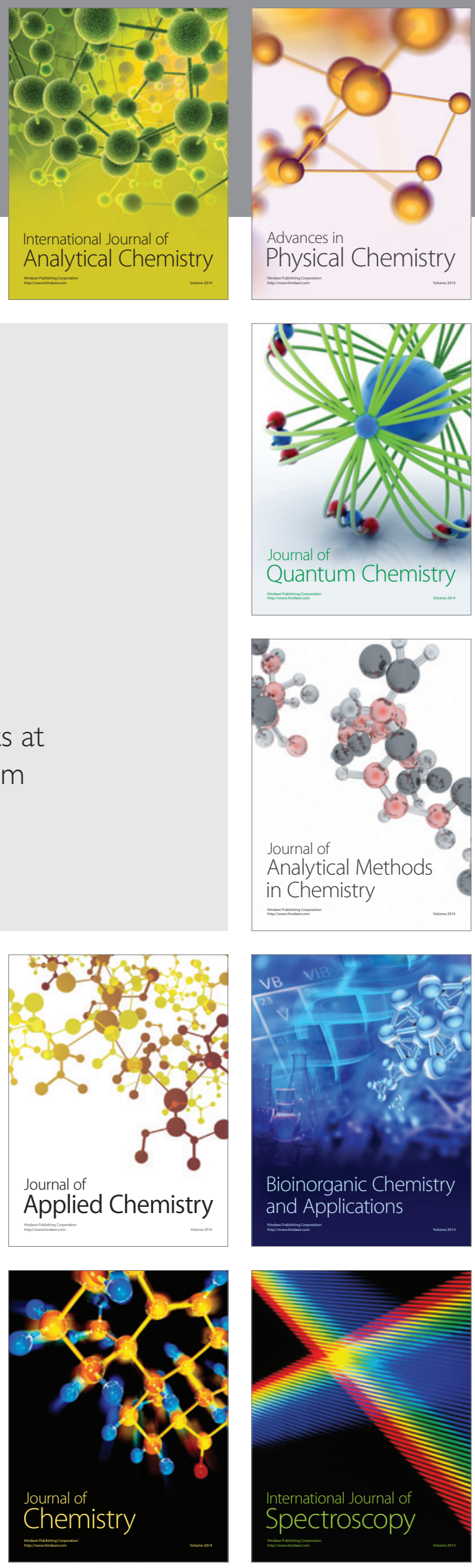